\title{
Advanced Glycation End Product (AGE) Accumulation in the Skin is Associated with Depression
}

Citation for published version (APA):

van Dooren, F. E. P., Pouwer, F., Schalkwijk, C. G., Sep, S. J. S., Stehouwer, C. D. A., Henry, R. M. A., Dagnelie, P. C., Schaper, N. C., van der Kallen, C. J. H., Koster, A., Denollet, J., Verhey, F. R. J., \& Schram, M. T. (2017). Advanced Glycation End Product (AGE) Accumulation in the Skin is Associated with Depression: The Maastricht Study. Depression and Anxiety, 34(1), 59-67.

https://doi.org/10.1002/da.22527

Document status and date:

Published: 01/01/2017

DOI:

10.1002/da.22527

Document Version:

Publisher's PDF, also known as Version of record

Document license:

Taverne

Please check the document version of this publication:

- A submitted manuscript is the version of the article upon submission and before peer-review. There can be important differences between the submitted version and the official published version of record.

People interested in the research are advised to contact the author for the final version of the publication, or visit the DOI to the publisher's website.

- The final author version and the galley proof are versions of the publication after peer review.

- The final published version features the final layout of the paper including the volume, issue and page numbers.

Link to publication

\footnotetext{
General rights rights.

- You may freely distribute the URL identifying the publication in the public portal. please follow below link for the End User Agreement:

www.umlib.nl/taverne-license

Take down policy

If you believe that this document breaches copyright please contact us at:

repository@maastrichtuniversity.nl

providing details and we will investigate your claim.
}

Copyright and moral rights for the publications made accessible in the public portal are retained by the authors and/or other copyright owners and it is a condition of accessing publications that users recognise and abide by the legal requirements associated with these

- Users may download and print one copy of any publication from the public portal for the purpose of private study or research.

- You may not further distribute the material or use it for any profit-making activity or commercial gain

If the publication is distributed under the terms of Article $25 \mathrm{fa}$ of the Dutch Copyright Act, indicated by the "Taverne" license above, 


\title{
Research Article
}

\section{ADVANCED GLYCATION END PRODUCT (AGE) ACCUMULATION IN THE SKIN IS ASSOCIATED WITH DEPRESSION: THE MAASTRICHT STUDY}

\author{
Fleur E. P. van Dooren, M.Sc., ${ }^{1,2,3}$ Frans Pouwer, Ph.D., ${ }^{2}$ Casper G. Schalkwijk, Ph.D., ${ }^{1,4}$
}

Simone J. S. Sep, Ph.D., ${ }^{1,4}$ Coen D. A. Stehouwer, Ph.D., ${ }^{1,4}$ Ronald M. A. Henry, Ph.D., ${ }^{1,4}$

Pieter C. Dagnelie, Ph.D., ${ }^{4,5,6}$ Nicolaas C. Schaper, Ph.D., ${ }^{1,4,5}$ Carla J. H. van der Kallen, Ph.D., ${ }^{1,4}$ Annemarie Koster, Ph.D., ${ }^{5,7}$ Johan Denollet, Ph.D., ${ }^{2}$ Frans R. J. Verhey, Ph.D., ${ }^{3}$ and Miranda T. Schram, Ph.D. ${ }^{1,4 *}$

Background: Depression is a bighly prevalent disease with a bigh morbidity and mortality risk. Its pathophysiology is not entirely clear. However, type 2 diabetes is an important risk factor for depression. One mechanism that may explain this association may include the formation of advanced glycation end products (AGEs). We therefore investigated the association of AGEs with depressive symptoms and depressive disorder. In addition, we examined whether the potential association was present for somatic and/or cognitive symptoms of depression. Methods: Cross-sectional data were used from the Maastricht Study ( $N=862$, mean age $59.8 \pm 8.5$ years, 55\% men). AGE accumulation was measured with skin autofluorescence (SAF) by use of the AGE Reader. Plasma levels of protein-bound pentosidine were measured with high-performance liquid chromatography and fluorescence detection. Ne-(carboxymethyl)lysine (CML) and $\mathrm{NE}$-(carboxyethyl)lysine (CEL) were measured with ultraperformance liquid chromatography and tandem mass spectrometry. Depressive symptoms and depressive disorder were assessed by the nine-item Patient Health Questionnaire and the Mini-International Neuropsychiatric Interview. Results: Higher SAF was associated with depressive symptoms $(\beta=0.42,95 \%$ CI 0.12-0.73, P $=$ $.007)$ and depressive disorder $(O R=1.42,95 \%$ CI 1.04-1.95, $P=.028)$ after adjustment for age, sex, type 2 diabetes, smoking, BMI, and kidney function. Plasma pentosidine, CML, and CEL were not independently associated with depressive symptoms and depressive disorder. Conclusions: This study shows that AGE accumulation in the skin is independently associated with higher levels of

\footnotetext{
${ }^{1}$ Department of Internal Medicine, Maastricht University Medical Centre, Maastricht, the Netherlands

${ }^{2}$ CoRPS-Center of Research on Psychology in Somatic diseases, Department of Medical and Clinical Psychology, Tilburg University, Tilburg, the Netherlands

${ }^{3}$ MHeNS-Alzheimer Centre Limburg, School for Mental Health and Neuroscience, Maastricht University, Maastricht, the Netherlands

${ }^{4}$ CARIM-Cardiovascular Research Institute Maastricht, Maastricht University, Maastricht, the Netherlands

${ }^{5}$ CAPHRI School for Public Health and Primary Care, Maastricht University, Maastricht, the Netherlands

${ }^{6}$ Department of Epidemiology, Maastricht University, Maastricht, the Netherlands
}

\footnotetext{
${ }^{7}$ Department of Social Medicine, Maastricht University, Maastricht, the Netherlands

*Correspondence to: Miranda T. Schram, Department of Internal Medicine, Maastricht University Medical Centre, p/a De Maastricht Studie, Randwycksingel 35, 6229 EG Maastricht, the Netherlands E-mail: m.schram@maastrichtuniversity.nl Received for publication 29 September 2015; Revised 22 February 2016; Accepted 13 March 2016
}

DOI 10.1002/da.22527

Published online 6 June 2016 in Wiley Online Library (wileyonlinelibrary.com).

(c) 2016 Wiley Periodicals, Inc. 
depressive symptoms and depressive disorder. This association is present for both somatic and cognitive symptoms of depression. This might suggest that AGEs are involved in the development of depression. Depression and Anxiety 34:59-67, 2017. (0) 2016 Wiley Periodicals, Inc.

Key words: depression; diabetes; advanced glycation end products; cobort

\section{INTRODUCTION}

$\mathrm{D}$ epression is an important global public health problem due to its relatively high lifetime prevalence and the significant disability that it causes. According to the World Health Organization (WHO), depression is the third leading cause of burden of disease as measured by Disability-Adjusted Lived Years, and is expected to be the leading cause in 2030. ${ }^{[1]}$ Therefore, the identification of its causes is a research priority. Although more and more research has been focusing on understanding the cause of depression, and several underlying mechanisms have been proposed, advanced glycation end products (AGEs) could present a novel mechanism in the etiology of diabetes and depression.

Type 2 diabetes mellitus (T2DM) is an important risk factor for depression, while it is associated with a $24 \%$ increased incidence of depression. ${ }^{[2]}$ This may suggest that prolonged hyperglycemia, a key feature of T2DM, is involved in the development of depression. Prolonged hyperglycemia accelerates the formation of AGEs, which are the irreversible products of a nonenzymatic reaction between glucose and proteins. ${ }^{[3]}$ AGEs can be measured in plasma (circulating AGEs, e.g., protein-bound $\mathrm{N} \varepsilon$ (carboxymethyl)lysine [CML], N $\varepsilon$-(carboxyethyl)lysine [CEL], and pentosidine) or estimated in tissue using a relatively simple noninvasive measurement of skin autofluorescence (SAF), a method based on the fluorescent properties of AGEs. ${ }^{[4]}$ SAF has been suggested to be a simple alternative to invasive measurement of AGE accumulation and has been shown to be correlated with fluorescent pentosidine and even nonfluorescent plasma AGEs CML and CEL in biopsy-derived skin tissue. ${ }^{[4]}$

A close link between depression and diabetes has been acknowledged for many years, but the exact nature of this relationship remains unclear. ${ }^{[5]}$ There is convincing evidence that the relationship between T2DM and depression is bidirectional. Depression has been identified as a risk factor for the development of $\mathrm{T} 2 \mathrm{DM}^{[6]}$ and the presence of T2DM can contribute to the onset of depression. ${ }^{[2]}$ AGEs form at a constant but slow rate in the normal body; however, their formation is markedly accelerated in diabetes due to prolonged hyperglycemia. ${ }^{[7]}$ Therefore, AGEs could present a novel mechanism in the etiology of depression and diabetes.

AGE accumulation has detrimental effects through at least three mechanisms: (1) activation of the receptor for AGEs (RAGE) results in increased inflammation and endothelial dysfunction; ${ }^{[8]}$ (2) intracellular accumulation of results in increased oxidative stress and endothelial dysfunction; ${ }^{[9,10]}$ and (3) the formation of cross-links with, for instance, collagen in the arterial wall leads to increased arterial stiffness. ${ }^{[1]}$ These three mechanisms are reflected by plasma levels of CML, CEL, and pentosidine, respectively, whereas SAF is a measure of tissue AGE accumulation.

Increased low-grade inflammation, endothelial dysfunction, and arterial stiffening are also implicated in the development of depressive symptoms. ${ }^{[12,13]}$ Thus, depression may contribute, via the inflammatory pathway, to the development of long-term complications of diabetes via acceleration of the formation of AGEs, and AGEs in turn may contribute to the development of depression. The latter is supported by studies that observed an association between glycated hemoglobin (HbAlc) levels, which is a measure of average plasma glucose concentrations and sustained hyperglycemia, and the incidence of depressive symptoms. ${ }^{[14,15]}$ Higher HbAlc levels can lead to more AGEs, ${ }^{[16]}$ and may thus lead to the incidence of depressive symptoms. Nevertheless, these associations between AGEs and depressive symptoms are unexplored.

In view of the above, we aim to evaluate whether there is an independent association of SAF and plasma AGEs with depressive symptoms and depressive disorder. As previous research suggests that mainly the somatic symptoms of depression and not the cognitive symptoms of depression are associated with adverse health phenomena, ${ }^{[17]}$ we additionally examined whether the potential association between AGEs and depressive symptoms is different for somatic symptoms compared with cognitive symptoms of depression. A final, subsidiary aim was exploring the association between AGEs and depression by diabetes diagnosis.

\section{MATERIALS AND METHODS}

\section{STUDY POPULATION}

In this study, we used data from the Maastricht Study, an observational prospective population-based cohort study. The rationale and methodology have been described previously. ${ }^{[18]}$ In brief, the study focuses on the etiology, pathophysiology, complications, and comorbidities of T2DM and is characterized by an extensive phenotyping approach. An extensive module on depressive symptoms and depressive disorder was part of the protocol. Eligible for participation were all individuals aged between 40 and 75 and living in the southern part of the Netherlands. Participants were recruited through mass media campaigns and from the municipal registries and the 
regional Diabetes Patient Registry via mailings. Recruitment was stratified according to known type 2 diabetes status for reasons of efficiency. The present report includes cross-sectional data from the first 866 participants, who completed the baseline survey between November 2010 and March 2012. The examinations of each participant were performed within a time window of 3 months. The study has been approved by the institutional medical ethical committee (NL31329.068.10) and the Minister of Health, Welfare and Sports of the Netherlands, on the basis of the Health Council's opinion (Permit 131088-105234-PG). All participants gave written informed consent.

\section{SKIN AUTOFLUORESCENCE}

SAF was measured with the AGE Reader (DiagnOptics Technologies $\mathrm{BV}$ ), which is a desktop device that uses the characteristic fluorescent properties of certain AGEs to estimate the level of AGE accumulation in the skin. More details of this noninvasive method have been described extensively elsewhere. ${ }^{[4,19]}$ In short, the AGE Reader illuminates a skin surface of $4 \mathrm{~cm}^{2}$ guarded against surrounding light, with an excitation wavelength range of $300-420 \mathrm{~nm}$, with a peak excitation of $370 \mathrm{~nm}$. SAF was calculated as the ratio between the emission light from the skin in the wavelength range of 420-600 nm (fluorescence) and excitation light that is reflected by the skin $(300-420 \mathrm{~nm})$, multiplied by 100 and expressed in arbitrary units (AU). Participants were asked not to use any sunscreen or self-browning creams on their lower arms within 2 days before the measurement. SAF was measured at room temperature in a semidark environment while participants were at rest in a seated position. The forearm of a participant was positioned on top of the device, as described by the manufacturer. The mean of three consecutive measurements was used in the analyses. Reproducibility was assessed in 14 individuals without diabetes (six males and eight females; mean age, $32.2 \pm 7.1$ years). The intraclass correlation coefficient (ICC) of three intraindividual consecutive SAF measurements was 0.83 (95\% CI 0.65-0.94). SAF was calculated offline by automated analysis using AGE Reader software, version 2.3, and was observer independent.

\section{ANALYSIS OF PROTEIN-BOUND AGES AND LYSINE IN PLASMA}

Plasma AGEs were measured in EDTA samples obtained from fasting venous blood, which were stored at $-80^{\circ} \mathrm{C}$ until analysis. Proteinbound pentosidine was quantified using high-performance liquid chromatography (HPLC) with fluorescence detection, as described in detail elsewhere. ${ }^{[20]}$ Intra- and interassay coefficients of variation $(\mathrm{CV})$ were 6.5 and $7.8 \%$ for pentosidine, respectively. Protein-bound CML, CEL, and lysine were quantified using ultraperformance liquid chromatography tandem mass spectrometry (UPLC MS/MS). ${ }^{[21]}$ Intraand interassay $C V_{\mathrm{S}}$ were 4.5 and $6.7 \%$ for $\mathrm{CML}, 6.2$ and $10.3 \%$ for CEL, and 5.0 and $5.3 \%$ for lysine. Concentrations of protein-bound pentosidine, CML, and CEL were adjusted for levels of lysine and expressed as nanomoles per millimole lysine.

\section{ASSESSMENT OF DEPRESSION}

Depressive disorder was assessed by the Mini-International Neuropsychiatric Interview (MINI). ${ }^{[22]}$ The MINI is a short diagnostic structured interview used to assess the presence of minor or major depressive disorder in the preceding 2 weeks according to the DSMIV (Diagnostic and Statistical Manual of Mental Disorders, Fourth Edition). Due to the low number of cases, we merged major and minor depression into a single variable. The MINI was conducted by trained staff members at the research center. Depressive symptoms in the preceding 2 weeks were assessed by a validated Dutch version of the nine-item Patient Health Questionnaire (PHQ-9). ${ }^{[23]}$ The PHQ-9 is a self-administered questionnaire based on the DMS$\mathrm{IV}^{[24]}$ criteria for a major depressive disorder. It comprises nine items rated on a 4-point scale, ranging from 0 (not at all) to 3 (nearly every day). Response options can generate a continuous score ranging from 0 (no symptoms) to 27 (all symptoms present nearly every day). Both cognitive symptoms of depression, comprising thoughts about oneself and problems of the mind, and somatic symptoms of depression, comprising various bodily sensations that a depressed individual perceives as unpleasant or worrisome, are measured with the PHQ-9. ${ }^{25]}$

\section{GENERAL CHARACTERISTICS AND COVARIATES}

Age, sex, partner status, diabetes duration in years, smoking behavior, alcohol consumption, and history of cardiovascular disease were assessed by means of a self-report questionnaire. ${ }^{[18]}$ Fasting venous blood samples were used to assess glucose levels, $\mathrm{HbA}_{1 \mathrm{c}}$, and lipid profile. Medication use was assessed by interview. Blood pressure was measured three times on the right arm after $10 \mathrm{~min}$ of seated rest, and the mean of these three measurements was used for analyses.

To determine T2DM status, all participants (except those who used insulin) underwent a standardized 7-point oral glucose tolerance test (OGTT) after an overnight fast. Blood samples are taken at baseline, and $15,30,45,60,90$, and $120 \mathrm{~min}$ after ingestion of a $75 \mathrm{~g}$ glucose drink. For safety reasons, participants with a fasting glucose level above $11.0 \mathrm{mmol} / \mathrm{l}$, as determined by a finger prick, do not undergo the OGTT. More details about this assessment method have been previously described. ${ }^{[18]}$ Individuals without type 1 diabetes and on diabetes medication were considered to have T2DM as well. ${ }^{[18]}$ Smoking behavior was based on self-report of smoking cigarettes, cigars, and/or pipe tobacco, and divided into three categories, that is, nonsmoker, former smoker, and current smoker. Additionally, lifetime smoking was expressed as pack-years; one pack-year was defined as one packet (20 cigarettes) per day, smoked over a course of 1 year. Alcohol consumption was categorized into nonconsumers, low consumers (less than or equal to seven glasses per week for women and $\leq 14$ glasses per week for men), and high consumers (more than seven glasses per week for women and $>14$ glasses per week for men). Weight, height, waist, and hip circumference were measured by a trained staff member, and body mass index (BMI) and waist-to-hip ratio were calculated. Glomerular filtration rate (eGFR) was estimated according to the CKD-EPI (Chronic Kidney Disease Epidemiology Collaboration) equation, based on serum creatinine. ${ }^{26]}$

\section{STATISTICAL ANALYSIS}

All analyses were performed by use of SPSS software, version 20 for Windows. Baseline characteristics were compared between individuals with and without depressive disorder by use of independent samples $t$-test for normally distributed continuous variables, Mann-Whitney $U$ test for continuous variables with a skewed distribution, and chisquare tests for categorical variables. Linear regression analyses were used to assess the associations of the four measures of AGEs (SAF, pentosidine, CML, and CEL) with depressive symptoms (PHQ-9). Logistic regression analyses were used to estimate the association of the four measures of AGEs (SAF, pentosidine, CML and CEL) with depressive disorder (MINI). Due to the low number of depression cases, we could only add a limited number of covariates in the analyses. Associations were adjusted for covariates; model 1 was the crude model; model 2 included the covariates age, sex, and T2DM. The latter might be an overadjustment given that AGEs accumulate more quickly with prolonged hyperglycemia and are thus presumably greater in people with type 2 diabetes. Model 3 additionally included smoking, BMI, 
and eGFR (fully adjusted model). The latter variables were included because the kidneys are the major way the body has for excreting AGEs to maintain the body load of AGEs at nontoxic levels. ${ }^{[27]}$ It has been shown that during aging and in diabetes, the glomerular basement membrane of the kidneys are thickened, leading to less efficient kidney filtration. ${ }^{[28]}$ A $P$-value $<0.05$ was considered statistically significant in two-sided tests.

In a secondary analysis, interaction analysis was performed to examine whether the associations between AGEs and depression differed between individuals with and without T2DM. For interaction terms, a $P$-value of $<0.05$ was considered statistically significant. In addition, factor analysis with principal axis factor extraction was used to explore the underlying factor structure of the PHQ-9. The decision about the number of factors to retain was guided by the eigenvalues from the unreduced correlation matrix, using the Kaiser-Guttman rule (eigenvalues $>1$, both the Kaiser-Meyer-Olkin measure of sampling adequacy and the Bartlett's test of sphericity were checked) and scree plot criterion. As the factors of the PHQ-9 were expected to be moderately correlated, oblique rotation (of the initial factor solution) was applied to simplify interpretation of the factor structure. Items loading $>|0.40|$ on one factor and $<|0.30|$ on any other factor after rotation were considered to meet the criteria for simple structure. ${ }^{[29]}$

\section{RESULTS}

\section{GENERAL CHARACTERISTICS}

The total sample consisted of 852 participants. Table 1 demonstrates general characteristics of the study population (55\% men, mean age 60 years), according to diagnosis of depressive disorder. Data on depression for the MINI interview were available in 852 individuals, PHQ-9 scores in 757. Missing data on depression scores were mainly due to not completing the questionnaires or refusal of the interview. Data on $S A F$ were available in 831 individuals, plasma AGEs in 843. Missing data on SAF were mainly due to device nonavailability or technical problems. Missing data on plasma AGEs were caused by difficulties in blood withdrawal. In total, $6.5 \%(n=55)$ of the participants scored positive for major or minor depressive disorder. These individuals had higher HbA1c levels, were more likely to smoke, and had higher levels of SAF. Levels of plasma AGEs pentosidine and CEL were not different in individuals with compared to individuals without depressive disorder, while plasma

TABLE 1. General characteristics of the Maastricht Study participants by diagnosis of depressive disorder

\begin{tabular}{|c|c|c|c|c|}
\hline & \multirow{2}{*}{$\begin{array}{l}\text { Total population } \\
\qquad(n=852)\end{array}$} & \multicolumn{2}{|c|}{ Depressive disorder $(n=852 ;$ MINI $)$} & \multirow[b]{2}{*}{$P$-value } \\
\hline & & No $(n=797)$ & Yes $(n=55)$ & \\
\hline Male sex $(n)$ & $55 \%(467)$ & $55 \%(438)$ & $53 \%(29)$ & $.748^{\mathrm{a}}$ \\
\hline Age (years) & $59.8 \pm 8.5$ & $59.8 \pm 8.5$ & $59.0 \pm 8.9$ & $.463^{\mathrm{b}}$ \\
\hline Having a partner $(n)$ & $85 \%(715)$ & $86 \%(673)$ & $76 \%(42)$ & $.063^{\mathrm{a}}$ \\
\hline T2DM $(n)$ & $29 \%(251)$ & $29 \%(229)$ & $40 \%(22)$ & $.076^{\mathrm{a}}$ \\
\hline Diabetes duration (years) & $8.4 \pm 6.9$ & $8.1 \pm 6.9$ & $10.4 \pm 6.7$ & $.176^{\mathrm{b}}$ \\
\hline HbA1c (\%) & $6.0 \pm 0.8$ & $6.0 \pm 0.8$ & $6.4 \pm 1.2$ & $.042^{\mathrm{c}}$ \\
\hline Fasting glucose level (mmol/L) & $6.1 \pm 1.5$ & $6.1 \pm 1.4$ & $6.6 \pm 2.6$ & $.140^{\mathrm{c}}$ \\
\hline Smoking (pack-years) & $14.6 \pm 21.5$ & $14.0 \pm 20.4$ & $23.9 \pm 33.6$ & $.002^{\mathrm{b}}$ \\
\hline Never/former/current (\%) & $31 / 53 / 16$ & $32 / 53 / 15$ & $19 / 51 / 30$ & $.009^{\mathrm{a}}$ \\
\hline Alcohol consumption No/low/high (\%) & $17 / 53 / 30$ & $17 / 53 / 30$ & $24 / 49 / 27$ & $.511^{\mathrm{a}}$ \\
\hline BMI $\left(\mathrm{kg} / \mathrm{m}^{2}\right)$ & $27.4 \pm 4.5$ & $27.3 \pm 4.5$ & $28.2 \pm 5.1$ & $.184^{\mathrm{b}}$ \\
\hline Waist circumference $(\mathrm{cm})$ & $97.2 \pm 13.6$ & $97.0 \pm 13.4$ & $99.6 \pm 15.8$ & $.175^{\mathrm{b}}$ \\
\hline Waist-to-hip ratio & $0.95 \pm 0.09$ & $0.95 \pm 0.09$ & $0.96 \pm 0.10$ & $.266^{\mathrm{b}}$ \\
\hline Systolic blood pressure (mmHg) & $137.4 \pm 19.0$ & $137.1 \pm 18.9$ & $141.0 \pm 20.4$ & $.141^{\mathrm{b}}$ \\
\hline Diastolic blood pressure (mmHg) & $76.7 \pm 10.3$ & $76.7 \pm 10.2$ & $77.5 \pm 12.3$ & $.544^{\mathrm{b}}$ \\
\hline Antihypertensive medication $(n)$ & $40 \%(342)$ & $40 \%(316)$ & $47 \%(26)$ & $.265^{\mathrm{a}}$ \\
\hline Total cholesterol $(\mathrm{mmol} / \mathrm{L})$ & $5.2 \pm 1.2$ & $5.2 \pm 1.2$ & $5.2 \pm 1.2$ & $.991^{\mathrm{b}}$ \\
\hline HDL-cholesterol (mmol/L) & $1.3 \pm 0.4$ & $1.3 \pm 0.4$ & $1.3 \pm 0.6$ & $.784^{\mathrm{b}}$ \\
\hline LDL-cholesterol (mmol/L) & $3.3 \pm 1.1$ & $3.3 \pm 1.0$ & $3.3 \pm 1.2$ & $.989^{\mathrm{b}}$ \\
\hline Triglycerides $(\mathrm{mmol} / \mathrm{L})$ & $1.5 \pm 1.0$ & $1.5 \pm 1.0$ & $1.7 \pm 0.9$ & $.113^{\mathrm{b}}$ \\
\hline Total-to-HDL cholesterol ratio & $4.5 \pm 8.6$ & $4.5 \pm 8.8$ & $4.5 \pm 1.5$ & $.970^{\mathrm{b}}$ \\
\hline Lipid-modifying medication $(n)$ & $37 \%(315)$ & $37 \%(292)$ & $42 \%(23)$ & $.441^{\mathrm{a}}$ \\
\hline History of CVD $(n)$ & $18 \%(147)$ & $18 \%(139)$ & $15 \%(8)$ & $.610^{\mathrm{a}}$ \\
\hline eGFR $\left(\mathrm{mL} / \mathrm{min} / 1.73 \mathrm{~m}^{2}\right)$ & $84.7 \pm 14.6$ & $84.7 \pm 14.7$ & $84.7 \pm 13.6$ & $.998^{\mathrm{b}}$ \\
\hline SAF (AU) & $2.71 \pm 0.53$ & $2.69 \pm 0.52$ & $2.87 \pm 0.59$ & $.021^{\mathrm{b}}$ \\
\hline Pentosidine (nmol/mmol LYS) & $0.52 \pm 0.30$ & $0.51 \pm 0.30$ & $0.55 \pm 0.28$ & $.405^{\mathrm{b}}$ \\
\hline CML (nmol/mmol LYS) & $74.22 \pm 14.69$ & $74.41 \pm 14.71$ & $71.57 \pm 14.26$ & $.166^{\mathrm{b}}$ \\
\hline CEL (nmol/mmol LYS) & $34.13 \pm 10.25$ & $34.18 \pm 10.15$ & $33.38 \pm 11.57$ & $.577^{\mathrm{b}}$ \\
\hline
\end{tabular}

Data are presented as mean \pm standard deviation unless otherwise indicated.

${ }^{\mathrm{a}}$ Chi-square.

${ }^{\mathrm{b}}$ Independent samples $t$-test.

${ }^{\mathrm{c}} t$-Test, equal variances not assumed. 


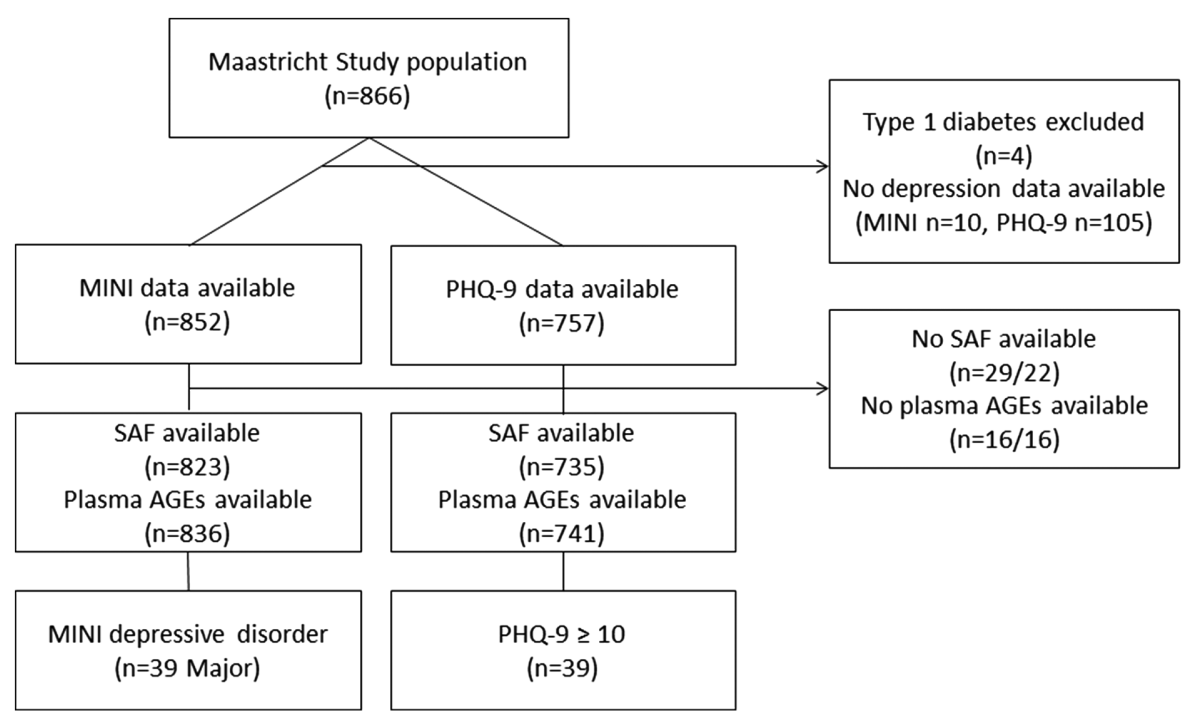

Figure 1. Flow diagram missing data.

levels of protein-bound CML were slightly higher in individuals without depressive disorder as compared to individuals with depressive disorder. Figure 1 depicts a flow diagram of the missing data.

\section{ASSOCIATIONS AMONG AGE ACCUMULATION, DEPRESSIVE SYMPTOMS, AND DEPRESSIVE DISORDER}

Table 2 shows a significant association of higher SAF with depressive symptoms (PHQ-9; $\beta=0.42,95 \% C I$ $0.12-0.73, P=.007)$ after adjustment for age, sex, T2DM status, smoking, BMI, and eGFR. In addition, $1 S D$ higher SAF was associated with a $42 \%$ higher odds of depressive disorder (MINI; fully adjusted model, 95\% CI $1.04-1.95, P=.028)$. Plasma pentosidine, plasma $\mathrm{CML}$, and plasma CEL were not associated with depressive symptoms (respectively; $\beta=0.23,-0.11,-0.16$ ) and depressive disorder (respectively; $O R=1.05,0.90,0.83$ ) after full adjustment.

\section{ADDITIONAL ANALYSES}

To determine whether the associations between AGEs and measures of depression were different across diabetes status, an interaction term was added to the regression models. No significant interactions were observed, suggesting that the relationship between AGEs and measures of depression were not different for individuals with or without T2DM.

Explanatory factor analysis was performed to explore the underlying factor structure and depression

TABLE 2. Associations among measures of AGE accumulation, depressive symptoms, and depressive disorder

\begin{tabular}{|c|c|c|c|c|c|c|c|}
\hline \multirow[b]{2}{*}{ Independent variable } & \multirow[b]{2}{*}{ Model } & \multicolumn{3}{|c|}{ Depressive symptoms (PHQ-9) } & \multicolumn{3}{|c|}{ Depressive disorder (MINI) } \\
\hline & & $\beta$ & $95 \% C I$ & $P$-value & $\overline{O R}$ & $95 \% \mathrm{CI}$ & $P$-value \\
\hline \multirow[t]{3}{*}{ SAF (AU) } & 1 & 0.19 & $-0.09 ; 0.46$ & .181 & 1.36 & $1.05-1.76$ & .021 \\
\hline & 2 & 0.42 & $0.12 ; 0.73$ & .007 & 1.52 & $1.14-2.04$ & .004 \\
\hline & 3 & 0.42 & $0.12 ; 0.73$ & .007 & 1.42 & $1.04-1.95$ & .028 \\
\hline \multirow{3}{*}{$\begin{array}{l}\text { Plasma pentosidine } \\
\text { (nmol/mmol LYS) }\end{array}$} & 1 & 0.20 & $-0.06 ; 0.45$ & .138 & 1.10 & $0.88-1.36$ & .409 \\
\hline & 2 & 0.30 & $0.04 ; 0.55$ & .023 & 1.12 & $0.91-1.39$ & .291 \\
\hline & 3 & 0.23 & $-0.02 ; 0.48$ & .067 & 1.05 & $0.81-1.36$ & .722 \\
\hline Plasma CML & 1 & -0.43 & $-0.69 ;-0.16$ & .002 & 0.82 & $0.61-1.09$ & .165 \\
\hline \multirow[t]{2}{*}{ (nmol/mmol LYS) } & 2 & -0.32 & $-0.59 ;-0.06$ & .018 & 0.87 & $0.65-1.16$ & .344 \\
\hline & 3 & -0.11 & $-0.39 ; 0.16$ & .421 & 0.90 & $0.65-1.23$ & .494 \\
\hline Plasma CEL & 1 & 0.03 & $-0.23 ; 0.30$ & .815 & 0.92 & $0.70-1.22$ & .577 \\
\hline \multirow{2}{*}{ (nmol/mmol LYS) } & 2 & -0.06 & $-0.32 ; 0.21$ & .672 & 0.88 & $0.66-1.17$ & .374 \\
\hline & 3 & -0.16 & $-0.42 ; 0.09$ & .212 & 0.83 & $0.61-1.12$ & .216 \\
\hline
\end{tabular}

Model 1 = crude.

Model 2 = model $1+$ age, sex, type 2 diabetes.

Model 3 = model $2+$ smoking, BMI, eGFR. 
TABLE 3. Associations between measures of AGE accumulation and cognitive and somatic symptoms of depression

\begin{tabular}{|c|c|c|c|c|c|c|c|}
\hline \multirow[b]{2}{*}{ Independent variable } & \multirow[b]{2}{*}{ Model } & \multicolumn{3}{|c|}{$\begin{array}{c}\text { Cognitive symptoms of depression } \\
\text { (PHQ-9) }\end{array}$} & \multicolumn{3}{|c|}{$\begin{array}{l}\text { Somatic symptoms of depression } \\
\text { (PHQ-9) }\end{array}$} \\
\hline & & $\beta$ & $95 \% C I$ & $P$-value & $\beta$ & $95 \% C I$ & $P$-value \\
\hline \multirow[t]{3}{*}{ SAF (AU) } & 1 & 0.09 & $-0.05 ; 0.23$ & .219 & 0.06 & $-0.07 ; 0.20$ & .333 \\
\hline & 2 & 0.20 & $0.04 ; 0.36$ & .016 & 0.15 & $0.00 ; 0.30$ & .049 \\
\hline & 3 & 0.19 & $0.02 ; 0.35$ & .024 & 0.16 & $0.02 ; 0.31$ & .031 \\
\hline \multirow{3}{*}{$\begin{array}{l}\text { Plasma pentosidine } \\
\text { (mmol/mmol LYS) }\end{array}$} & 1 & 0.08 & $-0.06 ; 0.21$ & .257 & 0.11 & $-0.01 ; 0.23$ & .078 \\
\hline & 2 & 0.13 & $-0.01 ; 0.26$ & .065 & 0.15 & $0.03 ; 0.27$ & .015 \\
\hline & 3 & 0.09 & $-0.05 ; 0.22$ & .204 & 0.13 & $0.01 ; 0.25$ & .032 \\
\hline Plasma CML & 1 & -0.21 & $-0.35 ;-0.07$ & .003 & -0.18 & $-0.31 ;-0.06$ & .003 \\
\hline \multirow{2}{*}{ (nmol/mmol LYS) } & 2 & -0.15 & $-0.29 ;-0.01$ & .040 & -0.15 & $-0.27 ;-0.03$ & .018 \\
\hline & 3 & -0.06 & $-0.21 ; 0.08$ & .389 & -0.06 & $-0.19 ; 0.08$ & .403 \\
\hline & 1 & -0.00 & $-0.14 ; 0.14$ & .974 & 0.04 & $-0.09 ; 0.12$ & .549 \\
\hline \multirow[t]{2}{*}{ (nmol/mmol LYS) } & 2 & -0.05 & $-0.19 ; 0.09$ & .498 & 0.00 & $-0.12 ; 0.12$ & .996 \\
\hline & 3 & -0.09 & $-0.23 ; 0.04$ & .177 & -0.06 & $-0.18 ; 0.07$ & .373 \\
\hline
\end{tabular}

Model $1=$ crude

Model $2=$ model $1+$ age, sex, type 2 diabetes.

Model $3=$ model $2+$ smoking, BMI, eGFR.

dimensions of the PHQ-9. Subsequent regression analyses was used to investigate whether differential associations between AGEs and various dimension of depression existed. The appropriateness of using this factor analysis was verified with both the Kaiser-Meyer-Olkin measure of sampling adequacy (0.912), and the Bartlett's test of sphericity $(P<.001)$. Two factors were extracted with eigenvalues $>1$, accounting for 52 and $11 \%$ of the total item variance. As expected, two latent factors underlie the PHQ-9, the first factor corresponding with cognitive symptoms of depression (lack of interest, depressed mood, negative feelings about oneself, concentration problems, psychomotor agitation/retardation, and suicidal ideation), and the second factor representing somatic symptoms of depression (sleeping problems, fatigability, and appetite problems). ${ }^{[30]}$ Both factors showed a high internal consistency, with Cronbach's alpha values of respectively .88 and .70 .

Higher SAF was significantly associated with both cognitive and somatic symptoms of depression $(\beta=0.19$, $95 \% C I 0.02-0.35, P=.024$ and $\beta=0.16,95 \% C I$ $0.02-0.31, P=.031$, respectively; Table 3 ), which suggests that the association of $S A F$ with depressive symptoms is not merely due to somatic symptoms, but due to depression as an illness itself. In addition, a positive association between pentosidine and both cognitive $(\beta=0.09,95 \% C I=-0.05-0.22, P=.204)$ and somatic symptoms $(\beta=0.13,95 \% C I 0.01-0.25, P=$ .032 ) of depression was shown; however, only statistically significant for somatic symptoms. Similar analyses showed negative associations between CML and both cognitive $(\beta=-0.06,95 \% C I=-0.21-0.08, P=.389)$ and somatic symptoms of depression $(\beta=-0.06,95 \%$ $C I-0.19-0.08, P=.403$ ), although not statistically significant. Analyses showed no association between CEL and both cognitive and somatic symptoms of depression (Table 3).

\section{DISCUSSION}

The present study is the first to our knowledge to investigate the association of AGEs with depressive symptoms and depressive disorder and has the following main findings. First, a higher level of SAF, a marker for tissue accumulation of AGEs, was significantly associated with depressive symptoms and depressive disorder. These results were independent of possible confounders, and did not differ between individuals with or without T2DM. Second, a high level of plasma pentosidine was borderline significantly associated with depressive symptoms. In addition, $S A F$ was associated with both cognitive and somatic symptoms of depression, while pentosidine was associated with somatic symptoms only. Finally, CML and CEL were not significantly associated with depressive symptoms or depressive disorder.

One possible mechanism that may explain our results is the cross-linking of AGEs leading to arterial stiffening. Several studies postulate that the formation of AGE cross-links in the arterial wall leads to increased arterial stiffening. ${ }^{[11,31,32]}$ Increased arterial stiffness leads to an increased pulsatile pressure load, which can damage the microcirculation, especially in the brain. ${ }^{[3,34]}$ This microvascular damage in the brain can manifest itself as white matter hyper intensities (WMH), cerebral microbleeds, and lacunar infarcts, which may ultimately result in depression. In support of this hypothesis, several longitudinal cohort studies ${ }^{[13,35]}$ show an independent association of arterial stiffness with depression in the general population.

Alternatively, activation of inflammatory pathways may play a role in the association between AGEs and depression. AGEs are known to activate the RAGE, which in turn activate genes that lead to the production of cytokines that can bind to many different pro-inflammatory molecules, thereby leading to an amplification of the inflammatory process, endothelial 
dysfunction, and oxidative stress. ${ }^{[36]}$ In addition, inflammation, oxidative stress, and endothelial dysfunction are known to be involved in the development of depression. ${ }^{[12,37]}$

In support of this hypothesis, levels of soluble RAGE (sRAGE), which can bind to AGEs and counteract their detrimental actions, ${ }^{[38]}$ are demonstrated to be lower in individuals with depression. ${ }^{[39,40]}$ This might suggest that high sRAGE levels could have a protective effect against the development of depression.

In contrast to SAF and pentosidine, we did not find any association among plasma CML, plasma CEL, and depression. As previously suggested, ${ }^{[21]}$ plasma levels of CML and CEL may not adequately reflect AGE accumulation in tissues. For instance, trapping of CML via RAGE in adipose tissue can cause a decrease in AGE plasma levels, ${ }^{[8]}$ while depression is frequently accompanied by obesity. ${ }^{[41]}$ Furthermore, plasma AGE levels are determined to a large extent by the half-life of plasma proteins, which is significantly shorter than the half-life time of long-lived proteins in the skin or the vascular wall. ${ }^{[42]}$

We found a significant association between SAF and both cognitive and somatic depressive symptoms by use of factor analysis. Previous research suggests that mainly the somatic symptoms of depression (e.g., sleeping problems, fatigue, appetitive problems) and not the cognitive symptoms of depression (e.g., depressed mood, negative feelings about oneself, concentration problems) are associated with adverse health outcomes in individuals with physical illness such as diabetes. ${ }^{[17]}$ The theory behind this is that somatic symptoms of depression are associated with metabolic risk factors for diabetes (obesity, dyslipidemia), or metabolic changes in diabetes and the associated inflammation may induce somatic symptoms of depression. ${ }^{[43]}$ Our findings suggest that the association between SAF and depressive symptoms is not limited to only somatic manifestations, but extends to depression as an illness, as cognitive symptoms were also associated with SAF.

The results of the present study should be interpreted in the light of some limitations. First, due to the crosssectional nature of the study, causal relationships are hard to determine, as AGE accumulation might be the cause or the result of having depressive symptoms. Depression can contribute to suboptimal glycemic control via less-adequate self-care behaviors, for example, lower levels of physical activity and unhealthy diet, ${ }^{[4]}$ and in turn can lead to the formation of AGEs. Depression may influence levels of oxidative stress directly via activation of the physiological stress axes. An increase in catecholamines, in response to stimulation of, for example, the sympatho-adrenal-medullary axis, is common in persons with depression; this may contribute to prooxidants activity, which in turn causes oxidative stress and subsequently to the formation of AGEs. ${ }^{[45]}$ The level of antioxidant concentrations was also found to be lower in case of more symptoms of depression, ${ }^{[46]}$ which can also lead to increased oxidative stress. Second, the percentage of participants with depressive symptoms or depressive disorder in our sample was relatively small compared with the prevalence of depression in other diabetes samples $(10-30 \%){ }^{[47]}$ This is possibly due to the fact that our study population is health conscious. The Maastricht Study selected those individuals who are able and/or willing to participate in four half-day visits to the research center. Moreover, participants received information about their health (e.g., do I have diabetes? Is my blood pressure OK?). As a result, participants showed a selection bias toward being health conscious and having a high educational level, and participants with type 2 diabetes were relatively healthy with a median diabetes duration of 8.4 years and a low prevalence of diabetes complications. The relatively small number of participants with depressive symptoms or depressive disorder limits the power of the current analyses. However, despite the relatively small numbers we were able to demonstrate significant and independent associations between SAF and depression. Without the selection bias, the effect estimates could be even stronger. Third, the AGE reader we used to assess tissue AGE accumulation only measures fluorescent AGEs. However, previous studies found a good correlation of $S A F$ with both fluorescent and nonfluorescent AGEs in skin biopsies. $^{[48]}$

Several strengths of the present study should also be highlighted. This is the first study that tested whether multiple markers of AGEs, both SAF and plasma AGEs, are associated with depression. In addition, depression status was extensively assessed, both by the PHQ-9 questionnaire and the MINI diagnostic interview. The extensive characterization of participants enabled us to adjust for multiple potential confounders.

\section{WIDER IMPLICATIONS AND GENERALIZABILITY OF THE FINDINGS}

We believe that we have conducted the first study that distinguished cognitive symptoms of depression versus somatic symptoms of depression in relation to AGEs. In addition, we are the first study that explores the association of pentosidine with depression. It is possible that the results that we found are only valid for our study sample, however, more studies are needed to confirm or reject our results.

In addition, in vitro and animal experiments have shown that various interventions can inhibit formation and/or actions of AGEs, in particular the specific AGE inhibitor aminoguanidine and the AGEs crosslink breaker alagebrium, and the $\mathrm{B}$ vitamins pyridoxamine and thiamine, and the latter's synthetic derivative benfotiamine. ${ }^{[49]}$ Although the potential clinical value of these interventions remains to be established, it could be a potential future intervention/treatment for AGE-induced depression. 


\section{CONCLUSION}

In conclusion, this study shows that AGE accumulation in the skin is independently associated with higher levels of depressive symptoms and depressive disorder. This association is both present for somatic and cognitive symptoms of depression. Additionally, pentosidine was found to be independently associated with somatic symptoms of depression. Our results might suggest that AGEs in the skin are involved in the development of depressive symptoms, possibly through the pathway of vascular stiffening, inflammation, or oxidative stress. Further research is needed to examine the causation of our observations.

Acknowledgments. This study was supported by the European Regional Development Fund via OPZuid, Province of Limburg, Dutch Ministry of Economic Affairs (grant 310.041). All below-mentioned parties contributed to the design and conduct of the study and collection, management, analysis, and interpretation of the data: Stichting De Weijerhorst (Maastricht, the Netherlands), the Pearl String Initiative Diabetes (Amsterdam, the Netherlands), the Cardiovascular Center (CVC, Maastricht, the Netherlands), School for Mental Health and Neuroscience (MHeNS, Maastricht, the Netherlands), Cardiovascular Research Institute Maastricht (CARIM, Maastricht, the Netherlands), School for Public Health and Primary Care (CAPHRI, Maastricht, the Netherlands), School for Nutrition, Toxicology and Metabolism (NUTRIM, Maastricht, the Netherlands), Stichting Annadal (Maastricht, the Netherlands), Health Foundation Limburg (Maastricht, the Netherlands) and unrestricted grants from Janssen-Cilag B.V. (Tilburg, the Netherlands), Novo Nordisk Farma B.V. (Alphen aan den Rijn, the Netherlands), and Sanofi-Aventis Netherlands B.V. (Gouda, the Netherlands). All the authors approved the manuscript and decided to submit the manuscript for publication.

Conflict of interest. The authors declare that they have no conflicts of interest.

\section{REFERENCES}

1. WHO. WHO statistics 2007. Available at: http://www.who.int/ whosis/whostat2007.pdf?ua $=1.2007$.

2. Nouwen A, Winkley K, Twisk J, et al. Type 2 diabetes mellitus as a risk factor for the onset of depression: a systematic review and meta-analysis. Diabetologia 2010;53(12):2480-2486.

3. Yamagishi S. Role of advanced glycation end products (AGEs) and receptor for AGEs (RAGE) in vascular damage in diabetes. Exp Gerontol 2011;46(4):217-224.

4. Meerwaldt R, Graaff R, Oomen PH, et al. Simple non-invasive assessment of advanced glycation endproduct accumulation. Diabetologia 2004;47(7):1324-1330.
5. Roy T, Lloyd CE. Epidemiology of depression and diabetes: a systematic review. J Affect Disord 2012;142 Suppl:S8-21.

6. Knol MJ, Twisk JW, Beekman AT, et al. Depression as a risk factor for the onset of type 2 diabetes mellitus. A meta-analysis. Diabetologia 2006;49(5):837-845.

7. Peppa M, Uribarri J, Vlassara H. Glucose, advanced glycation end products, and diabetes complications: what is new and what works. Clin Diabetes 2003;21(4):186-187.

8. Gaens KH, Stehouwer CD, Schalkwijk CG. Advanced glycation endproducts and its receptor for advanced glycation endproducts in obesity. Curr Opin Lipidol 2013;24(1):4-11.

9. Brouwers O, Niessen PM, Haenen G, et al. Hyperglycaemiainduced impairment of endothelium-dependent vasorelaxation in rat mesenteric arteries is mediated by intracellular methylglyoxal levels in a pathway dependent on oxidative stress. Diabetologia 2010;53(5):989-1000.

10. Brouwers O, Niessen PM, Ferreira I, et al. Overexpression of glyoxalase-I reduces hyperglycemia-induced levels of advanced glycation end products and oxidative stress in diabetic rats. J Biol Chem 2011;286(2):1374-1380.

11. Sell DR, Monnier VM. Molecular basis of arterial stiffening: role of glycation - a mini-review. Gerontology 2012;58(3):227-237.

12. van Sloten TT, Schram MT, Adriaanse MC, et al. Endothelial dysfunction is associated with a greater depressive symptom score in a general elderly population: the Hoorn Study. Psychol Med 2014;44(7):1403-1416.

13. Tiemeier H, Breteler MM, van Popele NM, et al. Late-life depression is associated with arterial stiffness: a population-based study. J Am Geriatr Soc 2003;51(8):1105-1110.

14. Hamer M, Batty GD, Kivimaki M. Haemoglobin A1c, fasting glucose and future risk of elevated depressive symptoms over 2 years of follow-up in the English Longitudinal Study of Ageing. Psychol Med 2011;41(9):1889-1896.

15. Aikens JE, Perkins DW, Lipton B, Piette JD. Longitudinal analysis of depressive symptoms and glycemic control in type 2 diabetes. Diabetes Care 2009;32(7):1177-1181.

16. Banser A, Naafs JC, Hoorweg-Nijman JJ, et al. Advanced glycation end products, measured in skin, vs. HbAlc in children with type 1 diabetes mellitus. Pediatr Diabetes 2015, accepted for publication.

17. Wiltink J, Michal M, Wild PS, et al. Associations between depression and diabetes in the community: do symptom dimensions matter? Results from the Gutenberg Health Study. PLoS One 2014;9(8):e105499.

18. Schram MT, Sep SJ, van der Kallen CJ, et al. The Maastricht Study: an extensive phenotyping study on determinants of type 2 diabetes, its complications and its comorbidities. Eur J Epidemiol 2014;29(6):439-451.

19. Spauwen PJ, van Eupen MG, Kohler S, et al. Associations of advanced glycation endproducts with cognitive functions in individuals with and without type 2 diabetes. J Clin Endocrinol Metab 2014:jc20142754.

20. Scheijen JL, van de Waarenburg MP, Stehouwer CD, Schalkwijk CG. Measurement of pentosidine in human plasma protein by a single-column high-performance liquid chromatography method with fluorescence detection. J Chromatogr B Analyt Technol Biomed Life Sci 2009;877(7):610-614.

21. Hanssen NM, Engelen L, Ferreira I, et al. Plasma levels of advanced glycation endproducts Nepsilon-(carboxymethyl)lysine, Nepsilon-(carboxyethyl)lysine, and pentosidine are not independently associated with cardiovascular disease in individuals with or without type 2 diabetes: the Hoorn and CODAM studies. J Clin Endocrinol Metab 2013;98(8):E1369-1373.

22. Sheehan DV, Lecrubier Y, Sheehan KH, et al. The Mini-International Neuropsychiatric Interview (M.I.N.I.): the 
development and validation of a structured diagnostic psychiatric interview for DSM-IV and ICD-10. J Clin Psychiatry 1998;59 Suppl 20:22-33; quiz 34-57.

23. Kroenke K, Spitzer RL, Williams JB. The PHQ-9: validity of a brief depression severity measure. J Gen Intern Med 2001;16(9):606-613.

24. American Psychiatric Association. Diagnostic and Statistical Manual of Mental Disorders. 4th ed. Washington, DC: American Psychiatric Association; 1994.

25. Smolderen KG, Spertus JA, Reid KJ, et al. The association of cognitive and somatic depressive symptoms with depression recognition and outcomes after myocardial infarction. Circ Cardiovasc Qual Outcomes 2009;2(4):328-337.

26. Levey AS, Stevens LA, Schmid CH, et al. A new equation to estimate glomerular filtration rate. Ann Intern Med 2009;150(9):604612.

27. Vlassara H, Uribarri J, Ferrucci L, et al. Identifying advanced glycation end products as a major source of oxidants in aging: implications for the management and/or prevention of reduced renal function in elderly persons. Semin Nephrol 2009;29(6):594603.

28. Radner W, Hoger H, Lubec B, et al. L-arginine reduces kidney collagen accumulation and N-epsilon-(carboxymethyl)lysine in the aging NMRI-mouse. J Gerontol 1994;49(2):M44-46.

29. Brown TA. Confirmatory Factor Analysis for Applied Research. New York: Guilford Press; 2006.

30. Krause JS, Reed KS, McArdle JJ. Factor structure and predictive validity of somatic and nonsomatic symptoms from the patient health questionnaire-9: a longitudinal study after spinal cord injury. Arch Phys Med Rehabil 2010;91(8):1218-1224.

31. Ueno H, Koyama H, Tanaka S, et al. Skin autofluorescence, a marker for advanced glycation end product accumulation, is associated with arterial stiffness in patients with end-stage renal disease. Metabolism 2008;57(10):1452-1457.

32. Schram MT, Schalkwijk CG, Bootsma AH, et al. Advanced glycation end products are associated with pulse pressure in type 1 diabetes: the EURODIAB Prospective Complications Study. Hypertension 2005;46(1):232-237.

33. Mitchell GF. Effects of central arterial aging on the structure and function of the peripheral vasculature: implications for end-organ damage. J Appl Physiol (1985) 2008;105(5):1652-1660.

34. O'Rourke MF, Safar ME. Relationship between aortic stiffening and microvascular disease in brain and kidney: cause and logic of therapy. Hypertension 2005;46(1):200-204.

35. Seldenrijk A, van Hout HP, van Marwijk HW, et al. Depression, anxiety, and arterial stiffness. Biol Psychiatry 2011;69(8):795-803.

36. Clynes R, Moser B, Yan SF, et al. Receptor for AGE (RAGE): weaving tangled webs within the inflammatory response. Curr Mol Med 2007;7(8):743-751.
37. Kohler O, Benros ME, Nordentoft M, et al. Effect of antiinflammatory treatment on depression, depressive symptoms, and adverse effects: a systematic review and meta-analysis of randomized clinical trials. JAMA Psychiatry 2014;71(12):13811391.

38. Schmidt AM, Yan SD, Yan SF, Stern DM. The multiligand receptor RAGE as a progression factor amplifying immune and inflammatory responses. J Clin Invest 2001;108(7):949955.

39. Emanuele E, Martinelli V, Carlin MV, et al. Serum levels of soluble receptor for advanced glycation endproducts (sRAGE) in patients with different psychiatric disorders. Neurosci Lett 2011;487(1):99-102.

40. Chen G, Wu Y, Wang T, et al. Association between serum endogenous secretory receptor for advanced glycation end products and risk of type 2 diabetes mellitus with combined depression in the Chinese population. Diabetes Technol Ther 2012;14(10):936-942.

41. Luppino FS, de Wit LM, Bouvy PF, et al. Overweight, obesity, and depression: a systematic review and meta-analysis of longitudinal studies. Arch Gen Psychiatry 2010;67(3):220-229.

42. Smit AJ, Hartog JW, Voors AA, van Veldhuisen DJ. Advanced glycation endproducts in chronic heart failure. Ann N Y Acad Sci 2008;1126:225-230.

43. Michal M, Wiltink J, Kirschner Y, et al. Differential associations of depressive symptom dimensions with cardio-vascular disease in the community: results from the Gutenberg health study. PLoS One 2013;8(8):e72014.

44. Pouwer F, Nefs G, Nouwen A. Adverse effects of depression on glycemic control and health outcomes in people with diabetes: a review. Endocrinol Metab Clin North Am 2013;42(3):529_ 544.

45. Bindoli A, Rigobello MP, Deeble DJ. Biochemical and toxicological properties of the oxidation products of catecholamines. Free Radic Biol Med 1992;13(4):391-405.

46. Tsuboi H, Tatsumi A, Yamamoto K, et al. Possible connections among job stress, depressive symptoms, lipid modulation and antioxidants. J Affect Disord 2006;91(1):63-70.

47. Ali S, Stone MA, Peters JL, et al. The prevalence of co-morbid depression in adults with type 2 diabetes: a systematic review and meta-analysis. Diabet Med 2006;23(11):1165-1173.

48. Mulder DJ, Water TV, Lutgers HL, et al. Skin autofluorescence, a novel marker for glycemic and oxidative stress-derived advanced glycation endproducts: an overview of current clinical studies, evidence, and limitations. Diabetes Technol Ther 2006;8(5):523535 .

49. Engelen L, Stehouwer CD, Schalkwijk CG. Current therapeutic interventions in the glycation pathway: evidence from clinical studies. Diabetes Obes Metab 2013;15(8):677-689. 